\title{
Preventing readmissions to hospital for asthma
}

\author{
E A Mitchell
}

Childhood asthma is one of the most prevalent diseases in childhood, ${ }^{1}$ with major social and economic costs for the family and child. Furthermore, in developed countries asthma is responsible for many admissions to hospital, ${ }^{2}$ many of which represent readmissions, so that up to $50 \%$ of all the children admitted for asthma will be readmitted in the following 12 months. ${ }^{3}$ If these readmissions could be reduced then the potential savings, both for the health service and families, are large.

In this issue Madge and colleagues ${ }^{4}$ report the results of a randomised controlled study of a nurse-led home management training programme in children admitted to hospital with acute asthma. The results are stunning; readmissions were only $8 \%$ over the 14 months study period in the intervention group compared with $25 \%$ in the control group. Reattendance at the hospital emergency room was unchanged.

The first question is "Are the results of the study valid?" The Evidence-Based Medicine Working Group proposed a number of criteria by which to judge the validity of such studies. ${ }^{5}$ The primary criteria were fulfilled: the assignment of patients to treatments was randomised, all patients who entered the trial were properly accounted for, follow up for assessment of readmissions was complete, and patients were analysed in the groups to which they were randomised. The secondary criteria were: (a) were the patients, health workers, and study personnel "blind" to treatment? (b) were the groups similar at the start of the trial? (c) aside from the experimental intervention, were the groups treated equally? Although the health workers were not "blind" to treatment group, it is unlikely that this would have influenced readmissions as the decision to readmit was made independently of the research team. The mean age of the intervention and control groups was significantly different, but the difference was quite small and this would not have explained their findings.

The results are important and the study is valid. The next question is "What was the intervention?" The intervention package consisted of asthma nurse-led teaching/discussion sessions, a booklet providing practical advice about asthma, a written individualised asthma management plan, peak flow meter for children over five, parental administered short course of oral steroids, and one appointment 2-3 weeks after discharge for a nurse-run asthma clinic.

The scientific evidence of the value of each of these components is variable. A meta-analysis of 11 randomised controlled studies of self-management teaching programmes in childhood asthma found that they had little effect on morbidity outcomes. ${ }^{6}$ Education programmes, including the use of written material, increases knowledge but are not necessarily accompanied by behavioural changes. ${ }^{7}$ Written asthma management plans have been included in most national guidelines for asthma management, ${ }^{89}$ although randomised controlled studies of their use are lacking. ${ }^{10}$ Monitoring peak expiratory flow (PEF) is also part of many guidelines. In children symptoms of asthma frequently precede changes in PEF which limits the use of PEF meters to "predict" the onset of asthma episodes. ${ }^{11}$ Monitoring symptoms may be equally useful. ${ }^{12}$ The few randomised controlled studies of PEF monitoring have produced inconsistent results. ${ }^{1314}$ The use of oral steroids in the management of acute asthma is well established. A meta-analysis of 30 studies found that the use of steroids early in the treatment of asthmatic exacerbations reduces admissions in both adults and children and they were also effective in preventing relapse in the outpatient treatment of asthmatic exacerbations. ${ }^{15}$ Unexpectedly, one recent double blind placebo controlled study of parental administered oral steroids at home reported a larger number of attacks resulting in outpatient visits associated with their use. ${ }^{16}$ Asthma clinics are a traditional part of medical practice but have not been subject to clinical trials. One observational study found they had no effect on readmission rates after controlling for potential confounders. ${ }^{3}$

The notable omission from the package of interventions in this study is an attempt to alter the child's environment. Both tobacco smoking, particularly by the mother, and house dust mite exposure are associated with an increase in asthmatic symptoms. ${ }^{1718}$ Smoking by parents of asthmatic children, although difficult to change, can be altered. ${ }^{19}$ Allergen avoidance studies have varied in their success. ${ }^{18}$

"Which component(s) of the intervention package are critical to the success?" Parental administered oral steroids would appear to be most important and could easily become part of the standard management of asthmatic children at discharge. Further trials are needed to assess the additional effect of education, written material, written management plans, PEF monitoring, nurse-led asthma clinics, parental smoking cessation, and allergen avoidance.

"How generalisable are the results?" Certainly the asthmatic children in the study appear to be typical of those admitted to hospital, but one cannot help wondering how much the success of the intervention was dependent upon the skill of the asthma educator. Extending this study into the community with the aim of preventing first admissions is warranted.

These trials are difficult to perform and are difficult to attract research funding. Ms Madge and colleagues are to be congratulated on a study well done, and on designing an intervention package which has resulted in very low asthma readmission rates.

Department of Paediatrics,

University of Auckland,

Private Bag 92019,

Auckland, New Zealand

E A MITCHELL

1 von Mutius E. Progression of allergey and asthma through childhood to adolescence. Thorax 1996;51(Suppl 1):S3-6.

2 Strachan DP, Anderson HR. Trends in hospital admission rates for asthm in children. $B M \mathcal{F} 1992 ; 304: 819-20$

3 Mitchell EA, Bland JM, Thompson JMD. Risk factors for readmission to hospital for asthma in childhood. Thorax 1994;49:33-6.

4 Madge P, McColl J, Paton J. Impact of a nurse-led home management training programme in children admitted to hospital with acute asthma: training programme in children admitted to hospital with

5 Guyatt GH, Sackett DL, Cook DJ. User's guides to the medical literature. Guyatt GH, Sackett DL, Cook DJ. User's guides to the medical literature.
II. How to use an article about therapy or prevention. A. Are the results

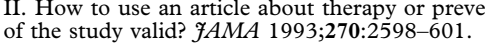

6 Bernard-Bonnin A-C, Stachenko S, Bonin D, Charette C, Rosseau E. Selfmanagement teaching programs and morbidity of paediatric asthma: a meta-analysis. F Allergy Clin Immunol 1995;95:34-41.

7 Garrett J, Fenwick JM, Taylor, Mitchell E, Stewart J, Rea H. Prospective controlled evaluation of the effect of a community based asthma education centre in a multiracial working class neighbourhood. Thorax 1994;49: 976-83.

8 National Heart, Lung, and Blood Institute, National Asthma Education Programme Expert Panel Report. F Allergy Clin Immunol 1991;88:425-534.

9 Warner JO. Asthma: a follow up statement from an International Paediatric Asthma Consensus Group. Arch Dis Child 1992;67:240-8. 
10 D'Souza W, Crane J, Burgess C, Te Karu H, Fox C, Harper M, Robson $\mathrm{B}$, et al. Community-based asthma care: trial of a "credit card" asthma self-management plan. Eur Respir $\mathcal{f} 1994 ; 7: 1260-5$.

11 Clough JB, Sly PD. Association between lower respiratory tract symptoms and falls in peak expiratory flow in children. Eur Respir f 1995;8:718-22.

12 Malo JL, L'Archeveque J, Trudeau C, d'Aquino C, Cartier-A. Should we monitor peak expiratory flow rates or record symptoms with a simple
diary in the management of asthma? $\mathcal{f}$ Allergy Clin Immunol 1993;91: $702-9$.

13 Jones KP, Mullee MA, Middleton M, Chapman E, Holgate ST. Peak flow based asthma self-management: a randomised controlled study in general practice. British Thoracic Society Research Committee. Thorax 1995;50: 851-7.

14 Ignacio-Garcia JM, Gonzalez-Santos P. Asthma self-management education program by home monitoring of peak expiratory flow. Am $\mathcal{F}$ Respir Crit Care Med 1995;151:353-9.
15 Rowe BH, Keller JL, Oxman AD. Effectiveness of steroid therapy in acute exacerbations of asthma: a meta-analysis. Am f Emerg Med 1992;10: $301-10$

16 Grant CC, Duggan AK, DeAngelis C. Independent parental administration of prednisone on acute asthma: a double-blind, placebo-controlled, crossover study. Pediatrics 1995;96:224-9.

17 Chilmonczyk BA, Salmun LM, Megathlin KN, Neveux LM, Palomaki GE Knight GJ, et al. Association between exposure to environmental tobacco smoke and exacerbations of asthma in children. N Engl f Med 1993;328: 1665-9.

18 Warner JA, Warner JO. Allergen avoidance in childhood asthma. Respir Med $1991 ; 85: 101-5$.

19 Hovell MF, Meltzer SB, Zakarian JM, Wahlgren DR, Emerson JA, Hofstetter CR, Leaderer BP, et al. Reduction of environmental tobacco smoke exposure among asthmatic children: a controlled trial. Chest 1994;106: 440-6 (published erratum appears in Chest 1995;107:1480). 